\title{
Estimation of genetic parameters and comparison of breeding values for body weight with different models in a South African Merino stud
}

\author{
K.R. Nemutandani ${ }^{1,2}$, M.A. Snyman ${ }^{1}$, W.J. Olivier $^{1} \&$ C. Visser ${ }^{2, \#}$ \\ ${ }^{1}$ Grootfontein Agricultural Development Institute, Private Bag X529, Middelburg (EC), 5900 \\ ${ }^{2}$ Department of Animal \& Wildlife Sciences, Faculty of Natural \& Agricultural Sciences, University of Pretoria, \\ 0002 \\ \# Corresponding author: carina.visser@up.ac.za
}

Email addresses: khetho.nemutandani@ul.ac.za (K.R. Nemutandani), GretaS@daff.gov.za (M.A. Snyman), WillemO@daff.gov.za (W.J. Olivier), Carina.Visser@up.ac.za (C.Visser) 


\section{Abstract}

Data collected on body weight from birth to 5 years of age in the Grootfontein Merino stud from 1968 to 2012 were analysed with univariate, multivariate and repeatability animal models. The estimated breeding values (EBVs) were compared to determine the most suitable statistical models for the estimation of EBVs. Measures of body weights included birth weight (BW), body weight at 42 days of age (W42), weaning weight (WW), body weight at 6 months (W6), 8 months (W8), 12 months (W12) and 15 months (W15) of age as well as adult weights recorded on the ewe flock from 2 to 5 years of age (AW2 to AW5). Univariate direct heritabilities were $0.20,0.42,0.16,0.54,0.43,0.37,0.51,0.43$, $0.40,0.31$ and 0.33 respectively. Multivariate direct heritabilities for WW, W12, W15 and AW3 were lower than those estimated with univariate models, namely $0.17,0.22,0.23$ and 0.29 respectively. Direct heritability obtained with the repeatability model was 0.26 . Maternal heritabilities for BW, W42, WW, W6, W8, and W15 were $0.11,0.15,0.04,0.28,0.18$ and 0.08 respectively. Lower multivariate maternal heritabilities were obtained for WW (0.02) and W15 (0.01). The genetic correlation between direct and maternal effects was negative for all weights where it was included, ranging from -0.28 for BW to -0.95 for W6. High genetic correlations were estimated between weights at different ages with multivariate analyses. When animals were selected on EBVs estimated with multivariate models, $92 \%$ of the animals selected retained the same ranking. When using the Top $1 \%$ lists, $95 \%$ and $94 \%$ of the animals selected on either univariate $(\mathrm{U})$ or multivariate (M) EBVs for W15 and WW respectively, would be identical. Selection based on univariate W15 EBVs, would possibly result in selection of different animals, due to lower rank correlations of $\mathrm{W} 15 \mathrm{U}$ with $\mathrm{WWU}(0.67)$ and $\mathrm{WWM}(0.80)$ respectively. The moderate to high estimates of heritability for body weight demonstrated that there is still considerable additive genetic variation in body weight available. The present study indicated that the multivariate model was the most appropriate model for estimating breeding values for body weight at selection age in the Grootfontein Merino stud.

Keywords: Linear models, multivariate, repeatability, univariate, breeding values 


\section{Introduction}

Growth is regarded as one of the most important traits for the selection of replacement animals in both wool and mutton sheep enterprises (Snyman \& Cloete, 2008), as the growth rate and body weight of lambs at different ages determine the profitability of the enterprise (Mohammadi et al., 2013; Ngere et al., 2017). Body weight is positively correlated with many other traits of economic importance, such as reproduction (Safari et al., 2007b; Olivier \& Cloete, 2011; Olivier, 2014), adaptability (Singh et al., 2016), wool production (Baneh et al., 2013; Olivier, 2014) and survival at birth (Baneh et al., 2013).

Over the past four decades, the focus of the South African Merino industry has been to increase body size, while ensuring that wool weight remains constant and fibre diameter is decreased (Olivier et al., 1995). Since 1996, the estimation of estimated breeding values (EBVs) has been done using a multiple trait model including body weight, clean fleece weight, fibre diameter and staple length. The current selection criteria of South African Merino sheep still mainly focus on growth and wool traits, but reproductive performance is also included (Herselman \& Olivier, 2010; Van Graan et al., 2014). These selection strategies have resulted in positive genetic responses in the traits under selection (Olivier et al., 1995, Olivier, 2014).

A number of growth traits can be included as selection criteria. Birth weight is positively correlated with body weight at all other ages (Al-Shorepy, 2001), and is also associated with survival rate (Borg, 2007). Pre-weaning growth rate and weaning weight determines marketing age in lambs that are marketed at an early age (Boujenane \& Diallo, 2017). Weaning weight is an important component of total weight of lamb weaned, which in turn determines ewe production efficiency. At least one measure of post weaning weight is routinely recorded in most sheep breeds and is usually related to the marketing weight of the breed. In South African Merino sheep, lambs could be marketed as early as 8 to 9 months of age under favourable conditions. The remaining animals that are not selected as replacement ewes or as castrated males for wool production are slaughtered at 15 to 18 months of age. Body weight at 12 to 16 months of age is included in the current selection index used for South African Merino sheep (Olivier et al., 2014).

Maternal effects affect early-expressed traits, such as pre-weaning and weaning weights. By including or omitting maternal effects, the accuracy of genetic parameters is influenced (Singh et al., 2016; Boujenane \& Diallo, 2017). Ignoring maternal effects generally leads to an overestimation of heritability values, and unrealistic expectations regarding the rate of genetic progress that can be 
achieved. It is important to apply the most appropriate model for the estimation of (co)variance components and genetic parameters for body weights. Restricted maximum likelihood models have been used extensively to estimate (co)variance components for body weight in sheep (Singh et al., 2016; Boujenane \& Diallo, 2017; Kumar et al., 2017; Ngere et al., 2017). These models partition the phenotypic variance of a quantitative trait into additive genetic variance, environmental variance and other effects such as maternal, common environmental, or permanent environmental effects (Meyer, 1989). Arguably the simplest method of analysis of data with repeated measures is the repeatability model. In this model, each observation is treated as a repeated record of the same trait in the same individual. This model has been implemented in the past for traits such as milk yield in successive lactations in dairy cattle (Jamrozik et al., 1997; Interbull, 2000), and more recently for milk production in dairy sheep (Murphy et al., 2017) and reproductive traits in Mehraban sheep (Yavarifard et al., 2015).

It is important that EBVs for performance traits should be estimated as accurately as possible. The aim of this study was to determine the most suitable statistical models for the estimation of breeding values for body weight in a South African Merino flock. Univariate, multivariate and repeatability animal models (Meyer \& Hill, 1997; Gilmour et al., 2014) were compared to evaluate ranking of animals and accuracy of EBVs obtained with these different models.

\section{Material and Methods}

Data collected on the Grootfontein Merino stud were used for this study. Maintenance and selection procedures followed in the stud were described in detail by Olivier $(1989,1998)$ and Olivier et al. (1995). The dataset used in this study comprised body weight data recorded at different ages in this stud from 1968 to 2012. The total number of males and females for which birth weight was recorded, were 7794 and 8317 respectively (Table 1). The traits recorded were birth weight (BW), body weight at 42 days of age (W42), weaning weight (WW), body weight at 6 months (W6), 8 months (W8), 12 months (W12) and 15 months (W15) of age and adult weights recorded on the ewe flock from 2 to 5 years of age. 
Table 1 Number of records, mean and coefficient of variation for body weights of ewes and rams

\begin{tabular}{|c|c|c|c|}
\hline Trait & Number of records & Mean $(\mathrm{kg})$ & Coefficient of variation (\%) \\
\hline \multicolumn{4}{|l|}{ Ewes } \\
\hline Birth weight & 8317 & 4.3 & 21.1 \\
\hline 42-Day body weight & 4077 & 16.5 & 24.5 \\
\hline Weaning weight & 7602 & 26.1 & 21.4 \\
\hline 6-Month body weight & 641 & 32.5 & 20.0 \\
\hline 8-Month body weight & 848 & 36.5 & 15.6 \\
\hline 12-Month body weight & 1679 & 40.5 & 14.6 \\
\hline 15-Month body weight & 6441 & 42.4 & 16.2 \\
\hline 2-Year body weight & 2590 & 52.0 & 13.1 \\
\hline 3-Year body weight & 2313 & 55.4 & 12.6 \\
\hline 4-Year body weight & 1817 & 56.6 & 12.7 \\
\hline 5-Year body weight & 1437 & 56.6 & 13.4 \\
\hline \multicolumn{4}{|l|}{ Rams } \\
\hline Birth weight & 7794 & 4.5 & 20.3 \\
\hline 42-Day body weight & 3782 & 17.5 & 25.1 \\
\hline Weaning weight & 7070 & 27.8 & 21.4 \\
\hline 6-Month body weight & 538 & 35.5 & 20.1 \\
\hline 8-Month body weight & 727 & 44.4 & 16.8 \\
\hline 12-Month body weight & 1515 & 53.7 & 23.7 \\
\hline 15-Month body weight & 4404 & 61.5 & 23.6 \\
\hline
\end{tabular}

The fixed effects tested for significance were year-season of birth, sex, birth status, rearing status, age of the dam and their respective two-way interactions. Birth status was indicated as single (1), twin (2) or triplet (3) when born, while rearing status was indicated by the numerical indicating birth status followed by a numerical indicating whether the individual was reared as a single, twin or triplet. Age of the animal at recording was included as a covariate. The PROC GLM procedure of the SAS statistical package was used to determine which of these fixed effects had a significant influence on the different body weights (SAS, 2016). 
The following model was applied for all body weights:

$Y_{i j k l m n}=\mu+y s_{i}+s_{j}+b s_{k}+r s_{I}+a d_{m}+\left(y s s_{i j}+b_{1} A L+e_{i j k l m n}\right.$

Where

$Y_{\mathrm{ijk} k m n}=$ trait of the n'th animal of the m'th age of dam of the l'th rearing status of the k'th birth status of the j'th sex of the i'th year-season of birth,

$\mu=$ overall mean,

$y s_{i}=$ fixed effect of the i'th year-season of birth (1968 to 2012; depending on weight),

$S_{j}=$ fixed effect of the j'th sex (ram, ewe),

$b s_{k}=$ fixed effect of the k'th birth status ( 1 - single , 2 - twin, 3 - triplet; only for birth weight),

$r S_{I}=$ fixed effect of the I'th rearing status $(11,21,22,31,32,33$; for all except birth weight),

$\mathrm{ad}_{\mathrm{m}}=$ fixed effect of the $\mathrm{m}^{\prime}$ th age of dam (2 to 7 years),

$(y s s) i j=$ effect of the interaction between the i'th year-season of birth and the j'th sex,

$b_{1}=$ linear regression coefficient of the appropriate deviation from the mean of age of the lamb at recording (AL; except for birth weight),

$\mathrm{e}_{\mathrm{ijk} k \mathrm{mn}}=$ random error with zero mean and variance $1 \sigma^{2} \mathrm{e}$.

Uni- and multivariate linear animal models were fitted with the ASReml program (Gilmour et al., 2014). Direct additive and maternal additive genetic effects, with or without a covariance between them, and maternal permanent environmental effects were tested for all traits in six different combinations. The six models were:

$$
\begin{aligned}
& y=X b+Z_{1} a+e \\
& y=X b+Z_{1} a+Z_{3} m p e+e \\
& y=X b+Z_{1} a+Z_{2} m+e ; \text { with } \operatorname{cov}(a, m)=0 \\
& y=X b+Z_{1} a+Z_{2} m+e ; \text { with } \operatorname{cov}(a, m)=A \sigma_{a m} \\
& y=X b+Z_{1} a+Z_{2} m+Z_{3} m p e+e ; \text { with } \operatorname{cov}(a, m)=0 \\
& y=X b+Z_{1} a+Z_{2} m+Z_{3} m p e+e ; \text { with } \operatorname{cov}(a, m)=A \sigma a m
\end{aligned}
$$

where y was a vector of observed traits of animals; $b, a, m$ and mpe were vectors of fixed effects, direct additive genetic effects, maternal additive genetic effects and maternal permanent 
environmental effects respectively; $X, Z_{1}, Z_{2}$ and $Z_{3}$ were incidence matrices respectively relating fixed effects, direct additive genetic effects, maternal additive genetic effects and maternal permanent environmental effects to $y$; e was the vector of residuals; A was a numerator relationship matrix, and $\sigma_{a m}$ was the covariance between direct additive genetic and maternal additive genetic effects. It was assumed that $\mathrm{V}(\mathrm{a})=\mathrm{A} \sigma^{2} \mathrm{a} ; \mathrm{V}(\mathrm{m})=\mathrm{A} \sigma^{2} \mathrm{~m} ; \mathrm{V}(\mathrm{mpe})=\mathrm{I} \sigma^{2} \mathrm{mpe} ; \mathrm{V}(\mathrm{e})=\mathrm{I} \sigma^{2} \mathrm{e}$, where I was an identity matrix, $\sigma_{\mathrm{a}}^{2}, \sigma^{2} \mathrm{~m}, \sigma^{2} \mathrm{mpe}$ and $\sigma^{2}$ e were the direct additive genetic variance, maternal additive genetic variance, maternal permanent environmental variance and environmental variance respectively. All components, with the phenotypic variance $\left(\sigma^{2} \mathrm{p}\right)$, being the sum of $\sigma^{2} \mathrm{a}, \sigma^{2} \mathrm{~m}, \sigma_{\mathrm{am}}, \sigma^{2} \mathrm{mpe}$, and $\sigma^{2}$, were derived at convergence.

Depending on the model, variance ratios were computed as direct heritability $\left(\mathrm{h}^{2}{ }_{\mathrm{a}}=\sigma_{\mathrm{a}}{ }^{2} / \sigma_{\mathrm{p}}{ }^{2}\right)$, maternal heritability $\left(\mathrm{h}^{2} \mathrm{~m}=\sigma_{\mathrm{m}}^{2} / \sigma_{\mathrm{p}}^{2}\right)$ and the direct-maternal covariance as proportion of phenotypic variance $\left(C_{a m}=\sigma_{a m} / \sigma_{p}{ }^{2}\right)$, with a corresponding estimate of the direct-maternal correlation $\left[r_{a m}=C_{a m} /\right.$ $\left.\sqrt{ }\left(\sigma a^{2} \times \sigma^{2}\right)\right]$. Similarly, the maternal environmental variance ratio was estimated by the permanent maternal environmental variance as a proportion of $\sigma_{\mathrm{p}}^{2}\left(\mathrm{c}^{2} \mathrm{mpe}=\sigma \mathrm{mpe} \mathrm{e}^{2} / \sigma_{\mathrm{p}}^{2}\right)$.

Different methods were used to determine the most suitable model for analysis. The likelihood ratio statistic [ $\log L ; \log \sigma=L\left(\mathrm{~b}_{2}\right)-L\left(\mathrm{~b}_{1}\right)$, where $L(\mathrm{~b})$ is the log likelihood function evaluated at the maximum likelihood estimator (b)], was one method used (Morrell, 1998). The statistic $-2\left(\log L_{2}-\log L_{1}\right)$ has a $x^{2}$ distribution with degrees of freedom equal to the difference between the number of parameters for the two models being compared. An effect was considered to have a significant influence when its inclusion caused a significant increase in log likelihood, compared to the model in which it was ignored. For the purpose of this study, a significance level of $P<0.05$ was applied throughout. Meyer (2004) stated that this test favours the model with the most parameters.

Akaike information criterion (AIC; Akaike, 1974), is AIC $=-2 \log L+2 k$, where $L$ is the likelihood and $\mathrm{k}$ is the number of parameters. The model with the smallest AIC is preferred. Schwarz Bayesian information criterion (BIC, Schwarz, 1978), is $\mathrm{BIC}=-2 \log \mathrm{L}+\mathrm{k} \log n$, where $\mathrm{L}$ is the likelihood, $\mathrm{k}$ is the number of parameters and $n$ is the number of observations (sample size). The model with the lower value of $\mathrm{BIC}$ is preferred.

Subsequently, a multivariate analysis, including weaning weight, 12-month body weight, 15month body weight and adult ewe body weight at three years of age, was done. The most suitable model for each trait, as determined under univariate analyses, was fitted for each weight. 
The estimation of the genetic parameters with repeatability models was also done with the ASReml program (Gilmour et al., 2014). Fixed effects for year-season of birth, sex, rearing status and age of the dam were included in the models. Direct additive and maternal additive genetic effects, with or without a covariance between them, animal permanent environmental effects and maternal permanent environmental effects were tested for all body weights in different combinations to yield six possible models. Two sets of these models were run. In the first, splines were fitted to separate ages $1,2,4,6,8,12,15,20,32,44,56$ and 68 months, while the second set of six models were run without the splines. The six models were:

$$
\begin{aligned}
& y=X b+Z_{1} a+W_{1} \text { anim }+e \\
& y=X b+Z_{1} a+W_{1} \text { anim }+W_{2} m p e+e \\
& y=X b+Z_{1} a+Z_{2} m+W_{1} \text { anim }+e ; \text { with } \operatorname{cov}(a, m)=0 \\
& y=X b+Z_{1} a+Z_{2} m+W_{1} \text { anim }+e ; \text { with } \operatorname{cov}(a, m)=A \sigma_{a m} \\
& y=X b+Z_{1} a+Z_{2} m+W_{1} \text { anim }+W_{2} m p e+e ; \text { with } \operatorname{cov}(a, m)=0 \\
& y=X b+Z_{1} a+Z_{2} m+W_{1} \text { anim }+W_{2} m p e+e ; \text { with } \operatorname{cov}(a, m)=A \sigma_{a m}
\end{aligned}
$$

where y was a vector of observed traits of animals; b, a, m, anim and mpe were vectors of fixed effects, direct additive genetic effects, maternal additive genetic effects, animal permanent environmental effects and maternal permanent environmental effects respectively; $X, Z_{1}, Z_{2}, W_{1}$ and $\mathrm{W}_{2}$ were incidence matrices respectively relating fixed effects, direct additive genetic effects, maternal additive genetic effects, animal permanent environmental effects and maternal permanent environmental effects to $y$; e was the vector of residuals; A was a numerator relationship matrix, and $\sigma_{a m}$ was the covariance between direct additive genetic and maternal additive genetic effects. It was assumed that $\mathrm{V}(\mathrm{a})=\mathrm{A} \sigma^{2} \mathrm{a} ; \mathrm{V}(\mathrm{m})=\mathrm{A} \sigma^{2} \mathrm{~m} ; \mathrm{V}(\operatorname{anim})=\mathrm{I} \sigma^{2}{ }_{\text {anim }} ; \mathrm{V}(\mathrm{mpe})=\mathrm{I} \sigma^{2} \mathrm{mpe} ; \mathrm{V}(\mathrm{e})=I \sigma^{2} \mathrm{e}$, where I was an identity matrix, $\sigma^{2} a, \sigma^{2} \mathrm{~m}, \sigma^{2}$ anim, $\sigma^{2}$ mpe and $\sigma^{2}$ were the direct additive genetic variance, maternal additive genetic variance, animal permanent environmental variance, maternal permanent environmental variance and environmental variance respectively. All components, with the phenotypic variance $\left(\sigma^{2} \mathrm{p}\right)$, were derived at convergence. The same statistics, namely, LogL, AIC and BIC were used to determine the most suitable model for analyses. 
EBVs were estimated for WW and W15, which are used for selection in the South African Small stock improvement scheme (NSIS). WW is used as selection criteria for reproduction, while W15 is the body weight included in the selection index at selection age as a measure of growth potential. AW3 was included as an indication of mature ewe body weight. As genetic correlations among the pre-weaning body weights, among the post-weaning weights and among the adult body weights are high and positive, the evaluation of EBVs for WW, W15 and ABW3 could be taken as representative of the different growth stages. The breeding values obtained for weaning weight, weight at 15 months and 3year body weight estimated using the most suitable univariate models, multivariate model and repeatability model, were compared. Estimated breeding values and accuracies of body weights of individual animals were obtained as back solutions with the ASReml program (Gilmour et al., 2014). Accuracy of EBVs were calculated as $\sqrt{ }\{1 \text { - [(predicted error variance reported with each BLUP value })^{2}$ / additive genetic variance of the specific trait]\}.

A dataset comprising EBVs for all animals with a 15-month body weight record was compiled. This implies that animals that had died before the age of 15 months were removed from the data set used for the following analyses. The Spearman rank correlation under the PROC CORR-procedure of SAS (SAS, 2016) was used to estimate the correlations between the ranks of these estimated breeding values for the different models. Furthermore, lists were compiled of the Top $10 \%$ and Top $1 \%$ of the animals having the highest EBVs for weaning weight, weight at 15 months and 3-year body weight, estimated with the different procedures. The number and percentage of animals common to the top lists were evaluated among the procedures.

\section{Results}

The number of records, means and coefficients of variation (CV) of the different body weights for the ewes and rams are presented in Table 1. The total number of records available for analysis ranged from 538 (rams) and 641 (ewes) for 6-month body weight to 7794 (rams) and 8317 (ewes) for birth weight, respectively. Relatively fewer records were available for 6-, 8- and 12-month body weights as body weights at these ages were not routinely recorded over the study period. The number of records decreased with age of ewes, due to culling and mortality. 
The results of the non-genetic effects tested for significance for each trait, are summarised in Table 2. Year-season of birth had a significant $(P<0.001)$ effect on all the traits studied, while sex and birth status had a significant $(P<0.001)$ effect on all the traits for which these effects were included.

Table 2 Significance level of the different non-genetic effects tested for the respective traits

\begin{tabular}{|c|c|c|c|c|c|c|c|c|c|}
\hline $\begin{array}{l}\text { 离 } \\
\stackrel{5}{\leftarrow}\end{array}$ & 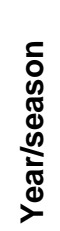 & $\begin{array}{l}\frac{5}{\underline{t}} \\
\frac{1}{0} \\
\frac{1}{0}\end{array}$ & હ & $\begin{array}{l}\frac{n}{2} \\
\frac{\pi}{\pi} \\
\frac{\pi}{n} \\
\frac{c}{n} \\
\frac{ \pm}{m}\end{array}$ & 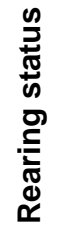 & $\begin{array}{l}\text { E } \\
\text { ত্ } \\
\frac{0}{0} \\
0 \\
\frac{0}{4}\end{array}$ & 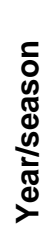 & 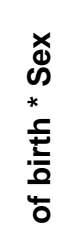 & 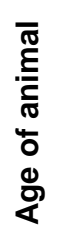 \\
\hline Birth weight & & * & * & * & - & ns & & ns & - \\
\hline 42-Day body weight & & * & * & - & * & ns & & ns & * \\
\hline Weaning weight & & * & * & - & * & * & & * & * \\
\hline 6-Month body weight & & * & * & - & * & * & & ns & * \\
\hline 8-Month body weight & & * & * & - & * & * & & * & * \\
\hline 12-Month body weight & & * & * & - & * & ns & & - & * \\
\hline 15-Month body weight & & * & * & - & * & * & & * & * \\
\hline 2-Year body weight & & * & - & - & ns & ns & & ns & ns \\
\hline 3-Year body weight & & * & - & - & ns & ns & & ns & ns \\
\hline 4-Year body weight & & * & - & - & ns & ns & & ns & ns \\
\hline 5-Year body weight & & * & - & - & ns & ns & & ns & ns \\
\hline
\end{tabular}

The Log L information criteria given in Table 3 indicate the most suitable model for each trait and were supported by the AIC and BIC criteria (data not shown). Model 6 which included all random effects, as well as the covariance between additive and maternal genetic effects was the most suitable model for BW, W42, W6 and W8. Model 5, including all the random effects, but excluding the covariance between the additive and maternal genetic effects was the most suitable for WW. The most suitable model (Model 2) for W12 included only the additive genetic and maternal permanent environmental effects, while Model 4, including additive and maternal genetic effects, as well as the covariance between these effects, was the most suitable model for W15. For all the adult body weights, either maternal genetic or maternal permanent environmental effects were included in addition to the additive genetic effect. For AW3 and AW5, Model 2 and Model 3 yielded the same results in terms of both 
information criteria and genetic parameters. Model 3 was chosen for further analyses and discussion of variances and genetic parameters.

Table 3 LogL values as a deviation from the most suitable model (Most suitable model highlighted)

\begin{tabular}{lllllll}
\hline Trait & M1 & M2 & M3 & M4 & M5 & M6 \\
\hline BW & 833.96 & 57.28 & 97.26 & 87.34 & 7.24 & 0 \\
W42 & 338.96 & 50.42 & 99.2 & 47.36 & 45.78 & 0 \\
WW & 973.50 & 26.34 & 56.92 & 55.48 & 2.20 & 0 \\
W6 & 14.60 & 7.26 & 13.84 & 9.46 & 7.26 & 0 \\
W8 & 38.30 & 13.58 & 31.64 & 20.84 & 13.58 & 0 \\
W12 & 6.78 & 0 & 4.64 & 3.34 & 0 & 0.46 \\
W15 & 52.20 & 44.68 & 34.04 & 1.30 & 34.04 & 0 \\
AW2 & 270.50 & 0 & 3.28 & 3.08 & 0 & 1.56 \\
AW3 & 179.08 & 0 & 0 & 1.32 & 0 & 1.06 \\
AW4 & 169.52 & 1.12 & 0.58 & 0 & 0.58 & 0 \\
AW5 & 133.26 & 0.02 & 0.02 & 0 & 0.02 & 0 \\
AW6 & 53.36 & 3.16 & 2.84 & 0 & 2.84 & 0 \\
\hline
\end{tabular}

$\mathrm{BW}=$ birth weight; $\mathrm{W} 42$ = body weight at 42 days of age; $\mathrm{WW}=$ Weaning weight; $\mathrm{W} 6$ = body weight at 6 months of age; W $8=$ body weight at 8 months of age; $\mathrm{W} 12=$ body weight at 12 months of age; $\mathrm{W} 15=$ body weight at 15 months of age; AW2 = adult body weight at two years; AW3 = adult body weight at three years; AW4 = adult body weight at four years; AW5 = adult body weight at five years; AW6 = adult body weight at six years

Table 4 summarises the (co)variance ratios for the various body weights obtained using the most suitable univariate model for each trait. Phenotypic variance increased with age until W15, after which it tended to plateau, while environmental variance kept increasing with an increase in age. No definite trend in direct genetic variance, maternal genetic variance or the maternal permanent environmental variance could be discerned with an increase in age. 
Table 4 (Co)variance components for the various body weights estimated with the most suitable univariate model for each weight

\begin{tabular}{lccccccc}
\hline Trait & Model & $\boldsymbol{\sigma}^{2} \mathbf{p}$ & $\boldsymbol{\sigma}^{2} \mathbf{a}$ & $\boldsymbol{\sigma}^{2} \mathbf{m}$ & $\boldsymbol{\sigma}^{2}$ mpe & $\boldsymbol{\sigma}_{\mathrm{am}}$ & $\boldsymbol{\sigma}^{2} \mathbf{e}$ \\
\hline BW & M6 & 0.570 & 0.117 & 0.065 & 0.071 & -0.025 & 0.343 \\
W42 & M6 & 12.003 & 5.084 & 1.748 & 1.272 & -2.407 & 6.306 \\
WW & M5 & 19.262 & 3.088 & 0.943 & 1.661 & 13.570 \\
W6 & M6 & 26.335 & 14.280 & 7.565 & 3.829 & -9.860 & 10.521 \\
W8 & M6 & 28.980 & 12.571 & 5.131 & 5.982 & -7.436 & 12.732 \\
W12 & M2 & 29.608 & 10.837 & & 1.375 & 17.396 \\
W15 & M4 & 34.264 & 17.558 & 2.693 & & -3.540 & 17.553 \\
AW2 & M2 & 28.466 & 12.357 & & 1.476 & 14.633 \\
AW3 & M3 & 31.525 & 12.467 & 0.000 & & & 19.059 \\
AW4 & M3 & 34.315 & 10.569 & 0.736 & & & 23.010 \\
AW5 & M3 & 34.223 & 11.397 & 0.000 & & & 22.826
\end{tabular}

$\sigma_{\mathrm{p}}^{2}=$ Phenotypic variance; $\sigma^{2}{ }_{\mathrm{a}}=$ direct additive variance; $\sigma^{2} \mathrm{~m}=$ maternal additive variance; $\sigma^{2} \mathrm{mpe}=$ maternal permanent environmental variance; $\sigma_{\mathrm{am}}=$ genetic covariance between the animal effects; $\sigma^{2}{ }_{\mathrm{e}}=$ environmental variance; BW = birth weight; $\mathrm{W} 42$ = body weight at 42 days of age; $\mathrm{WW}=$ weaning weight; $\mathrm{W} 6=$ body weight at 6 months of age; $\mathrm{W} 8=$ body weight at 8 months of age; $\mathrm{W} 12=$ body weight at 12 months of age; $\mathrm{W} 15=$ body weight at 15 months of age; AW2 = adult body weight at two years; AW3 = adult body weight at three years; AW4 = adult body weight at four years; AW5 = adult body weight at five years

Table 5 presents the genetic parameters for the different body weights obtained using the most suitable model for each trait. Direct heritability estimates were medium to high, ranging from 0.16 (WW) to 0.54 (W6). No definite trend was observed for direct heritability with increasing age. Maternal heritability values were lower than the corresponding direct heritabilities for all body weights, with the highest value of 0.28 reported for W6. The $\mathrm{c}^{2}$ mpe estimates ranged from 0.05 for $\mathrm{W} 12$ and AW2 to 0.21 for W8. The genetic correlation between direct and maternal effects was negative for all weights where it was included. The relatively high standard errors of the parameters estimated for 6- and 8-month body weight could most probably be ascribed to the fewer records available for these traits, namely less than 1200 for W6 and less than 1600 for W8. 
Table 5 Direct additive heritability $\left(\mathrm{h}^{2} \mathrm{a}\right)$, maternal heritability $\left(\mathrm{h}^{2}{ }_{\mathrm{m}}\right)$, maternal permanent environmental effect $\left(\mathrm{c}^{2} \mathrm{mpe}\right)$ and the genetic correlation between the animal effects $\left(r_{a m}\right)$ for the various body weights $( \pm$ s.e.) estimated with univariate models

\begin{tabular}{|c|c|c|c|c|c|}
\hline Trait & Model & $h^{2} a$ & $h^{2} m$ & $\mathrm{c}^{2} \mathrm{mpe}$ & $\mathrm{ram}_{\mathrm{am}}$ \\
\hline BW & M6 & $0.20 \pm 0.03$ & $0.11 \pm 0.02$ & $0.12 \pm 0.01$ & $-0.28 \pm 0.09$ \\
\hline W42 & M6 & $0.42 \pm 0.06$ & $0.15 \pm 0.03$ & $0.10 \pm 0.02$ & $-0.81 \pm 0.05$ \\
\hline WW & M5 & $0.16 \pm 0.02$ & $0.04 \pm 0.01$ & $0.09 \pm 0.01$ & \\
\hline W6 & M6 & $0.54 \pm 0.15$ & $0.28 \pm 0.17$ & $0.15 \pm 0.05$ & $-0.95 \pm 0.14$ \\
\hline W8 & M6 & $0.43 \pm 0.11$ & $0.18 \pm 0.08$ & $0.21 \pm 0.04$ & $-0.93 \pm 0.10$ \\
\hline W12 & M2 & $0.37 \pm 0.05$ & & $0.05 \pm 0.02$ & \\
\hline W15 & M4 & $0.51 \pm 0.04$ & $0.08 \pm 0.02$ & & $-0.51 \pm 0.06$ \\
\hline AW2 & M2 & $0.43 \pm 0.05$ & & $0.05 \pm 0.03$ & \\
\hline AW3 & M3 & $0.40 \pm 0.05$ & $0.00 \pm 0.00$ & & \\
\hline AW4 & M3 & $0.31 \pm 0.06$ & $0.02 \pm 0.03$ & & \\
\hline AW5 & M3 & $0.33 \pm 0.06$ & $0.00 \pm 0.00$ & & \\
\hline
\end{tabular}

$\mathrm{h}^{2}{ }_{\mathrm{a}}=$ direct heritability; $\mathrm{h}^{2} \mathrm{~m}=$ maternal heritability; $\mathrm{c}^{2} \mathrm{mpe}=$ maternal permanent environmental effect; $\mathrm{r}_{\mathrm{am}}=$ genetic correlation between direct and maternal effects; BW = birth weight; $\mathrm{W} 42$ = body weight at 42 days of age; $\mathrm{WW}=$ Weaning weight; W6 = body weight at 6 months of age; W8 = body weight at 8 months of age; W12 = body weight at 12 months of age; W15 = body weight at 15 months of age; AW2 = adult body weight at two years; AW3 = adult body weight at three years; AW4 = adult body weight at four years; AW5 = adult body weight at five years

The (co)variance components, correlations and heritabilities obtained with multivariate analyses of WW, W12, W15 and AW3 are summarised in Table 6. Direct heritability increased from $0.17 \pm 0.02$ for WW to $0.29 \pm 0.04$ for AW3. Phenotypic correlations among the traits ranged from low $(0.36 \pm 0.02$ between WW and AW3) to high (0.73 \pm 0.01 between W12 and W15). Genetic correlations were generally high and ranged from $0.69 \pm 0.05$ between $W 12$ and $W 15$ to $0.85 \pm 0.05$ between WW and W12. 
Table 6 Covariance components, correlations and heritabilities among WW, W12, W15 and AW3 obtained with multivariate analyses

\begin{tabular}{|c|c|c|c|c|c|}
\hline Trait & Parameter & WW & W12 & W15 & AW3 \\
\hline WW & $\sigma_{p 1 p 2}$ & 22.387 & 16.932 & 14.950 & 12.030 \\
\hline W12 & $\sigma_{p 1 p 2}$ & & 58.723 & 46.328 & 33.808 \\
\hline W15 & $\sigma_{p 1 p 2}$ & & & 67.799 & 39.852 \\
\hline AW3 & $\sigma_{\mathrm{p} 1 \mathrm{p} 2}$ & & & & 51.143 \\
\hline WW & $\sigma_{\mathrm{a} 1 \mathrm{a} 2}$ & 3.851 & 5.980 & 6.477 & 5.757 \\
\hline W12 & $\sigma_{\mathrm{a} 1 \mathrm{a} 2}$ & & 12.792 & 9.828 & 10.032 \\
\hline W15 & $\sigma_{\mathrm{a} 1 \mathrm{a} 2}$ & & & 15.967 & 11.644 \\
\hline AW3 & $\sigma_{\mathrm{a} 1 \mathrm{a} 2}$ & & & & 14.852 \\
\hline WW & $\sigma^{2} m$ & 0.411 & & & \\
\hline W15 & $\sigma^{2} m$ & & & 0.419 & \\
\hline WW & $\sigma^{2}$ mpe & 1.861 & & & \\
\hline W12 & $\sigma^{2}$ mpe & & 0.000 & & \\
\hline WW & $\sigma_{\mathrm{e} 1 \mathrm{e} 2}$ & 16.234 & 10.952 & 8.473 & 6.273 \\
\hline W12 & $\sigma_{\mathrm{e} 1 \mathrm{e} 2}$ & & 45.931 & 36.500 & 23.775 \\
\hline W15 & $\sigma_{\mathrm{e} 1 \mathrm{e} 2}$ & & & 51.413 & 28.208 \\
\hline AW3 & $\sigma_{\mathrm{e} 1 \mathrm{e} 2}$ & & & & 36.291 \\
\hline WW & $r_{p 1 p 2}$ & - & $0.47 \pm 0.01$ & $0.38 \pm 0.01$ & $0.36 \pm 0.02$ \\
\hline W12 & $r_{p 1 p 2}$ & & - & $0.73 \pm 0.01$ & $0.62 \pm 0.02$ \\
\hline W15 & $r_{p 1 p 2}$ & & & - & $0.68 \pm 0.01$ \\
\hline AW3 & $r_{p 1 p 2}$ & & & & - \\
\hline WW & $r_{g 1 g 2}$ & - & $0.85 \pm 0.05$ & $0.83 \pm 0.04$ & $0.76 \pm 0.06$ \\
\hline W12 & rg1g2 & & - & $0.69 \pm 0.05$ & $0.73 \pm 0.07$ \\
\hline W15 & $r_{g 1 g 2}$ & & & - & $0.76 \pm 0.05$ \\
\hline AW3 & $r_{g 1 g}$ & & & & - \\
\hline WW & $\mathrm{h}^{2} \mathrm{a}$ & $0.17 \pm 0.02$ & & & \\
\hline W12 & $h^{2} a$ & & $0.22 \pm 0.03$ & & \\
\hline W15 & $h^{2} a$ & & & $0.23 \pm 0.02$ & \\
\hline AW3 & $\mathrm{h}^{2} \mathrm{a}$ & & & & $0.29 \pm 0.04$ \\
\hline WW & $\mathrm{h}^{2} \mathrm{~m}$ & $0.02 \pm 0.01$ & & & \\
\hline W15 & $\mathrm{h}^{2} \mathrm{~m}$ & & & $0.01 \pm 0.0$ & \\
\hline
\end{tabular}




\begin{tabular}{|c|c|c|c|c|c|}
\hline Trait & Parameter & WW & W12 & W15 & AW3 \\
\hline WW & $c^{2}$ mpe & $0.08 \pm 0.01$ & & & \\
\hline W12 & $\mathrm{C}^{2}{ }_{\text {mpe }}$ & & $0.00 \pm 0.00$ & & \\
\hline
\end{tabular}

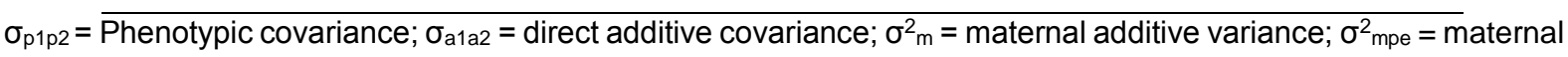
permanent environmental variance; $\sigma_{\mathrm{e} 1 \mathrm{e} 2}=$ environmental covariance; $r_{\mathrm{p} 1 \mathrm{p} 2}=$ phenotypic correlation; $r_{\mathrm{g} 1 \mathrm{~g} 2}=\mathrm{genetic}$ correlation; $h^{2}{ }_{a}=$ direct heritability; $h^{2} m=$ maternal heritability; $c^{2}$ mpe = maternal permanent environmental effect; $\mathrm{WW}=$ weaning weight; $\mathrm{W} 12$ = body weight at 12 months of age; W15 = body weight at 15 months of age; AW3 = adult body weight at three years

According to the Log L, AIC and BIC values, Model 3 without splines was identified as the most appropriate model for estimation of genetic parameters for body weight using a repeatability model. Variance components and genetic parameters estimated with the respective models are presented in Table 7.

Table 7 Variance component and genetic parameter estimates for body weight estimated with the most suitable repeatability model

\begin{tabular}{lc}
\hline \multicolumn{1}{c}{ Parameter } & Model 3 \\
\hline$\sigma^{2}{ }_{p}$ & 30.056 \\
$\sigma^{2}{ }_{a}$ & 7.918 \\
$\sigma^{2}{ }_{m}$ & 2.341 \\
$\sigma^{2}{ }^{a n i m}$ & 3.332 \\
$\sigma^{2}{ }^{2}$ & 16.466 \\
$\mathrm{~h}^{2}{ }_{a}$ & $0.26 \pm 0.06$ \\
$\mathrm{~h}^{2} \mathrm{~m}$ & $0.08 \pm 0.03$ \\
$\mathrm{c}^{2}{ }^{a n i m}$ & $0.11 \pm 0.05$ \\
$\mathrm{t}$ & $0.37 \pm 0.04$
\end{tabular}

$\sigma^{2}{ }_{p}=$ Phenotypic variance; $\sigma^{2}{ }_{a}=$ direct additive variance; $\sigma^{2} \mathrm{~m}=$ maternal additive variance; $\sigma^{2}{ }_{\text {anim }}=$ animal permanent environmental variance; $\sigma^{2}{ }_{e}=$ environmental variance; $h^{2}{ }_{a}=$ direct additive heritability; $h^{2} m=$ maternal heritability; $c^{2}$ anim = animal permanent environmental effect; $t=$ repeatability

Higher direct additive heritability values were obtained with the univariate models $(U)$ for W12 (0.37 vs. 0.22$)$, W15 (0.51 vs. 0.23 ) and AW3 (0.40 vs. 0.29$)$ compared to the multivariate (M) model. The maternal heritability values followed the same trend, with higher values estimated for both WW and 
W15 using the univariate model. As the repeatability model (REP) yielded one heritability for body weight overall, it is not possible to compare repeatability model values with specific uni- or multivariate values for each of the different body weights.

Spearman rank correlations between EBVs obtained with univariate, multivariate and repeatability animal models for WW, W15 and AW3 were estimated for all animals in the pedigree file with a 15-month body weight data record (Table 8). High correlations were obtained between the EBV rankings of WWU, W15U, WWM and W15M, while much lower correlations were observed between univariate estimates at 3 years of age (AW3U) and the other traits. These correlations increased when AW3 was included in the multivariate analyses. High correlations were estimated among EBVs of the traits included in the multivariate model, while low correlations were obtained between the rankings of the repeatability model EBVs and all other EBVs.

Table 8 Spearman rank correlations between EBVs obtained with univariate, multivariate and repeatability animal models for WW, W15 and AW3 using all animals with 15-month body weight data

\begin{tabular}{lccccccc}
\hline Trait & WWU & W15U & AW3U & WWM & W15M & AW3M & REP \\
\hline WWU & - & 0.67 & 0.26 & 0.85 & 0.70 & 0.70 & 0.30 \\
W15U & & - & 0.23 & 0.80 & 0.88 & 0.77 & 0.27 \\
AW3U & & & - & 0.32 & 0.25 & 0.52 & 0.12 \\
WWM & & & & - & 0.92 & 0.92 & 0.26 \\
W15M & & & & & - & 0.91 & 0.23 \\
AW3M & & & & & & - & 0.22
\end{tabular}

$W W \bar{U}=$ Weaning weight univariate; $W 15 U$ = 15-month body weight univariate; AW3U = 3-year adult body weight univariate; $\mathrm{WWM}=$ Weaning weight multivariate; $\mathrm{W} 15 \mathrm{M}=15$-month body weight multivariate; $\mathrm{AW} 3 \mathrm{M}=3-\mathrm{year}$ adult body weight multivariate; REP = Repeatability model; All correlations significant $(P<0.001)$

The number and proportion of common animals in the Top 10\% and Top 1\% lists are presented in Table 9 for EBVs estimated with the different models for weaning weight, 15-month body weight and 3-year body weight. The highest percentage common animals for the Top $10 \%$ lists was between the W15U and W15M lists which had $64.36 \%$ animals in both lists. The same applied for the Top $1 \%$ lists, where $95.33 \%$ common animals were present in the W15U and W15M lists. The lists involving the repeatability model EBVs had the least number of common animals. For all traits, the Top $1 \%$ lists had a higher percentage common animal than the Top $10 \%$ lists. 
Table 9 The number and proportion of common animals in the Top 10\% and Top 1\% lists when animals with a 15month body weight data record were included

\begin{tabular}{|c|c|c|c|c|}
\hline \multirow[t]{2}{*}{ Models } & \multicolumn{2}{|c|}{$\begin{array}{l}\text { Top } 10 \% \text { list } \\
(n=1069)\end{array}$} & \multicolumn{2}{|c|}{$\begin{array}{l}\text { Top } 1 \% \text { list } \\
(n=107)\end{array}$} \\
\hline & Number & $\%$ & Number & $\%$ \\
\hline WWU vs WWM & 658 & 61.55 & 101 & 94.39 \\
\hline WWU vs REP & 385 & 36.01 & 53 & 49.53 \\
\hline WWM vs REP & 391 & 36.58 & 44 & 41.12 \\
\hline W15U vs W15M & 688 & 64.36 & 102 & 95.33 \\
\hline W15U vs REP & 362 & 33.86 & 48 & 44.86 \\
\hline W15M vs REP & 376 & 35.17 & 37 & 34.58 \\
\hline AW3U vs AW3M & 468 & 43.78 & 93 & 86.92 \\
\hline AW3U vs REP & 174 & 16.28 & 22 & 20.56 \\
\hline AW3M vs REP & 333 & 31.15 & 27 & 25.23 \\
\hline
\end{tabular}

WWU = Weaning weight univariate; $\mathrm{W} 15 \mathrm{U}=15$-month body weight univariate; AW3U = 3-year adult body weight univariate; $\mathrm{WWM}=$ Weaning weight multivariate; $\mathrm{W} 15 \mathrm{M}=15$-month body weight multivariate; $\mathrm{AW} 3 \mathrm{M}=3$-year adult body weight multivariate; REP = Repeatability model

Table 10 The mean, minimum and maximum of the accuracies (\%) of the EBVs of all animals in the pedigree for WW, W15 and AW3 obtained with univariate, multivariate and repeatability animal models

\begin{tabular}{lccc}
\hline Trait & Mean & Minimum & Maximum \\
\hline WWU & 56.77 & 34.78 & 91.96 \\
W15U & 67.29 & 12.28 & 95.70 \\
AW3U & 40.90 & 3.57 & 78.98 \\
WWM & 63.88 & 43.71 & 93.73 \\
W15M & 64.56 & 38.25 & 93.95 \\
AW3M & 57.99 & 30.44 & 86.27 \\
REP & 26.51 & 0.14 & 88.19
\end{tabular}

WWU = Weaning weight univariate; $\mathrm{W} 15 \mathrm{U}=15$-month body weight univariate; $\mathrm{AW}$ UU = 3-year adult body weight univariate; $\mathrm{WWM}=$ Weaning weight multivariate; $\mathrm{W} 15 \mathrm{M}=15$-month body weight multivariate; $\mathrm{AW} 3 \mathrm{M}=3$-year adult body weight multivariate; REP = Repeatability model 
The mean, minimum and maximum of the accuracies of the EBVs of all animals in the pedigree for WW, W15 and AW3 obtained with univariate, multivariate and repeatability animal models are presented in Table 10. EBVs for WWM, W15U and W15M had the highest mean accuracies, while EBVs obtained with the repeatability model had the lowest accuracy.

\section{Discussion}

It is important in any breeding program that the genetic and environmental components of variance for the traits under selection are known, in order to estimate accurate genetic parameters for incorporation in downstream applications. As far as the environmental effects are concerned, the yearseason of birth had a significant effect on the weight of the animals throughout their lives. These differences in body weight could be ascribed to a range of factors, from maternal body condition score before mating to seasonal differences in grazing quality for mature animals. Male lambs were heavier than females, with a significant difference observed until 15 months of age. Single-born lambs were heavier at birth and W42, while single-raised lambs had a weight advantage from weaning until W15. The influence of non-genetic factors on growth traits corresponded to those reported in literature (Thiruvenkadan et al., 2008; Boujenane \& Diallo, 2017; Kumar et al., 2017; Jawasreh et al., 2018).

The Log L, AIC and BIC information criteria results were in agreement for all traits and based on these, the most suitable univariate model was identified for body weight at each age. Models incorporating both additive and permanent environmental maternal effects best described body weights up to 8 months of age. The magnitude of maternal effects highlighted the importance of accounting for these effects, as failure to do so will result in overestimation of heritability and unlikely expectations with regard to the rate of genetic progress that can realistically be achieved. Maternal variance was further partitioned into genetic and permanent environmental factors to better describe the dam environment's influence.

The moderate direct heritability of $0.20 \pm 0.03$ estimated with the univariate model for BW suggests that selection for this trait will be successful and corresponds to previously reported values of 0.18 (Safari et al., 2007a) to 0.35 (Wuliji et al., 2001) in Merino sheep. This estimate was also in line with parameters previously estimated in South African Merino sheep (Duguma et al., 2002; Cloete et al., 2003; Olivier, 2014). The permanent environmental maternal effect of 0.12 and maternal heritability of 0.11 estimated in this study indicates the importance of the maternal environment at birth, although 
the additive maternal value was lower than most previous reports (Duguma et al., 2002; Cloete et al., 2003; Safari et al., 2007a; Olivier, 2014). Both maternal heritability and the permanent environmental maternal effect declined from birth to weaning.

The $\mathrm{h}^{2} \mathrm{a}$ estimate for $\mathrm{W} 42$ of 0.42 estimated in this study was above the range reported in literature for Merino pre-weaning weights ( 2 to 5 months of age), which ranged from 0.09 to 0.37 (Lewer et al., 1994; Mortimer \& Atkins, 1995; Analla \& Serradilla, 1998; Wuliji et al., 2001; Olivier, 2014). The $\mathrm{h}^{2} \mathrm{~m}$ of 0.15 , however, fell within the range previously reported.

The $\mathrm{h}^{2}{ }_{\mathrm{a}}$ of 0.16 for weaning weight estimated in this study was lower than most previous estimates for South African Merino sheep (Cloete et al., 2001 (0.18); Olivier et al., 2001 (0.21 and 0.30); Duguma et al., $2002(0.26)$ ), but higher than the 0.09 estimated by Olivier (2014) and 0.13 by Cloete et al. (2003). The lower direct heritability estimated in this flock compared to the other studies mentioned, could apart from genetic differences, most probably be ascribed to the impact of varying environmental conditions. The Grootfontein Merino stud was subjected to varying environmental conditions for the last 10 years of the recording period, with corresponding weaning weights ranging from $27 \mathrm{~kg}$ to $37 \mathrm{~kg}$ among the years.

At weaning, the maternal influence is still expected to be high. The relatively low maternal heritability of 0.04 obtained in this study was comparable to the lower end of the values reported for weaning weight in Merino sheep, while the maternal permanent environmental effect $(0.09)$ was within the range previously reported (Snyman et al., 1996; Cloete et al., 2001; Wuliji et al., 2001; Duguma et al., 2002; Cloete et al., 2003; Olivier, 2014). Although weaning weight is lowly heritable in this stud and is influenced by maternal effects, it is an important trait that influence the economic viability of the enterprise as it directly contributes to income through an earlier marketing age and indirectly through the higher number of ewes that can be kept owing to the shorter production cycle.

The $h^{2}{ }_{a}(0.54 \pm 0.15)$ and $h^{2} m(0.28 \pm 0.17)$ estimated for $W 6$ in this study were higher than the estimates reported in literature which ranged from 0.18 to 0.44 and 0.04 to 0.12 , respectively (Snyman et al., 1996; Wuliji et al., 2001; Ingham et al., 2003; Olivier, 2014) on Merino sheep. Limited results are available for this age in previously published literature. However, the high parameter values obtained for W6 and W8 in this study is in contrast with the available literature reports and might have been influenced by incomplete W6 and W8 data. The relatively high standard errors for the estimates are evidence of this. 
Heritability estimates reported for older post-weaning weights varies markedly with age of the animals (12 to 18 months), with a corresponding wide range of estimates. The heritability values for W12 (0.37) and W15 (0.51) corresponded to high values ( 0.47 and 0.49 respectively) reported by Olivier (2014) in South African Merino sheep. After 8 months of age, the magnitude of maternal effects declined rapidly. For W15 and adult weights from 3 years, the maternal effect was genetic rather than environmental.

The heritabilities estimated in this study differed from those estimated on this flock in previous studies (Olivier et al., 1994; Olivier et al., 2001). Direct (0.51 vs. 0.38) and maternal (0.08 vs. 0.01) heritabilities for W15 were higher than those estimated by Olivier et al. (1994), while direct heritability for WW was lower in the current study (0.16) than in the previous study (0.21) of Olivier et al. (2001). Genetic changes due to response to selection for body weight (Olivier et al., 1995) and different management practices most probably contributed to these differences.

Neither the univariate direct variance and heritability or the univariate maternal variance and heritability in this study show a specific trend, which is not in line with most reported results. In most flocks, direct variance and heritability increase with age from weaning onwards, while maternal variance and heritability decrease with an increase in age (Snyman et al., 1995; Vaez Torshizi et al., 1996; Ngere et al., 2017). However, the univariate phenotypic variance in this study did show an increase with age of the animal. The structure of the data and completeness of pedigree influence the model's ability to disentangle genetic and environmental effects (Gerstmayer, 1991; Maniatis \& Pollott, 2003; Boligon et al., 2012). The limited number of records and incomplete dataset for W6 and W8 most probably impacted on these results.

Correlation estimates between direct and maternal genetic effects ranged from low negative at birth $(-0.28)$ to high negative at 6 months of age $(-0.95)$. The sign and magnitude of the direct-maternal correlation varies between different studies done on different breeds under different conditions. The majority of the reported estimates are negative for Merino sheep and ranged from -0.20 to -0.59 (Mortimer \& Atkins, 1995; Vaez Torshizi et al., 1996; Olivier, 2014). Only two positive estimates of 0.05 (Duguma et al, 2002) and 0.57 (Snyman et al., 1996) could be found for Merino sheep. This negative correlation between the direct and maternal effects should be kept in mind when including early body weights in the breeding plan, as selection progress could be less than expected when only considering the heritabilities. 
Multivariate additive variance components were higher than the univariate additive variance for a specific body weight and tended to increase with age of the animal. Direct heritabilities estimated with multivariate models were lower than the respective heritabilities obtained with univariate analyses for W12, W15 and AW3, but was the same for WW. Miraei-Ashtiani et al. (2007) reported similar direct heritabilities for BW, W6 and W12 with uni- and multivariate models, but a higher heritability for WW with the multivariate model. Including the traits in the multivariate model accounted for the direct as well as maternal genetic correlations among the traits. These genetic relationships among the traits consequently affected the genetic parameters estimated with the multivariate model.

Maternal genetic variance was lower when estimated with the multivariate model compared to the univariate model for WW (0.411 vs. 0.943$)$ and W15 (0.419 vs. 2.693). The same applied for the maternal permanent environmental variance for $\mathrm{W} 12$, which decreased from 1.375 with the univariate model to 0.00 with the multivariate model. The corresponding multivariate variance ratios were also lower. Phenotypic variance of W12, W15 and AW3 were much higher with the multivariate model than with univariate analysis. This consequently led to higher multivariate residual variance components for these body weights.

With the multivariate model, direct genetic correlations of W15 with WW, W12 and AW3 were estimated at $0.83 \pm 0.05,0.69 \pm 0.05$ and $0.76 \pm 0.05$ respectively. The strong positive genetic correlation between weights at different ages has been well described and was expected (Safari et al., 2007b; Olivier, 2014). Selection based on W15, as is currently the case in the South African Merino breed, will have a positive response on body weights at all other ages.

As with the univariate models, a combination of LogL, AIC and BIC information criteria were used to determine the most suitable repeatability model for each trait. The model without fitting splines was the most suitable model for estimating the (co)variance components and genetic parameters for body weight in this instance. The direct heritability for body weight using the repeatability model for this study was $0.26 \pm 0.06$, which compared favourably with the average of the heritability estimates using multivariate analysis. The estimated repeatability of 0.37 for body weight from birth weight to 5 years of age was higher than the range of 0.19 to 0.26 reported in studies on three Canadian breeds (Hansen \& Shrestha, 2002) and the Cradock fine wool Merino stud (Olivier, 2014). Estimates exceeding 0.46 were reported in several other studies (Hatcher et al., 2005; Wolc et al., 2011; Boujenane et al., 2013). 
The medium to high direct additive heritability estimates indicate that selection for growth traits can have positive results in a relatively short time. Both maternal direct and permanent environmental effects will influence these results. The negative correlation between direct and maternal additive genetic effects should be kept in mind, as it will slow down selection response.

The EBVs for body weight for Merino sheep obtained with the different models were compared using Spearman rank correlations, accuracy of EBVs, as well as the number and proportion of common animals in the Top 10\% and Top 1\% lists. The Spearman rank correlation was used to estimate the correlation between the ranking of animals on estimated breeding values for WW, W15 and AW3. When animals were selected on EBVs estimated with multivariate models, $92 \%$ of the animals selected on any of the body weights had the same ranking. This corresponds with the high genetic correlations estimated among WW, W15 and AW. Furthermore, when using the Top $1 \%$ lists, 95\% and $94 \%$ of the animals selected on either uni- or multivariate EBVs for W15 and WW respectively, would be identical. The highest accuracies for EBV were also calculated for univariate and multivariate WW and W15 analyses. However, if selection is based on univariate W15 EBVs, the possibility is greater that different animals will be selected, due to the lower rank correlation of W15U with WWU (0.67) and WWM (0.80) respectively. EBVs estimated with the repeatability models is unsuitable for use, as these had the lowest accuracies and there will be major re-ranking of animals when repeatability model EBVs and any of the other EBVs are used. No comparable literature reports on comparison of EBVs of body weights of sheep with different statistical models could be found.

\section{Conclusion}

The moderate to high estimates of heritability for body weight demonstrated that although being subjected to selection for increased body weight for many years, there is still considerable additive genetic variation in body weight available in this study. Body weights up to 8 months of age were influenced by maternal additive and permanent maternal environmental effects. The significant maternal effects for early body weights confirm that it must be included in the models for estimation of breeding values. The results of the present study indicate that the multivariate model is the most appropriate model for estimating breeding values for body weight at selection age in the Grootfontein Merino stud. 


\section{References}

Akaike, H., 1974. A new look at the statistical model identification. IEEE Trans. Automat. Contr. 19, 716-723.

Al-Shorepy, S.A., 2001. Estimates of genetic parameters for direct and maternal effects on birth weight of local sheep in United Arab Emirates. Small Rumin. Res. 39, 219-224.

Analla, M. \& Serradilla, J.M., 1998. Estimation of correlations between ewe litter size and maternal effects on lamb weights in Merino sheep. Genet. Sel. Evol. 30, 493-501.

Baneh, H., Mohammad Rokouei, M.,Ghafouri-Kesbi, F., Veysi, A. \& Niknafs, S., 2013. Multivariate genetic analysis on body weight traits in Ghezel sheep. Songklanakarin J. Sci. Technol. 35 (2), 131-135.

Boligon, A.A., Pereira, R.J., Ayres, D.R. \& Albuquerque, L.G., 2012. Influence of data structure on the estimation of the additive genetic direct and maternal covariance for early growth traits in Nellore cattle. Livest. Sci. 145, 212-218.

Borg, R,C., 2007. Phenotypic and genetic evaluation of fitness characteristics in sheep under a range environment. Ph.D. Thesis. Virginia University.

Boujenane, I., Chikhi, A., Sylla, M. \& Ibnelbachyr, M., 2013. Estimation of genetic parameters and genetic gains for reproductive traits and body weight of D'man ewes. Small Rumin. Res. 113, 4046.

Boujenane, I. \& Diallo, I.T., 2017. Estimates of genetic parameters and genetic trends for pre-weaning growth traits in Sardi sheep. Small Rumin. Res. 146, 61-68.

Cloete, S.W.P., Olivier, J.J., Van Wyk, J.B., Erasmus, G.J. \& Schoeman, S.J., 2003. Genetic parameters and trends for birth weight, birth coat score and weaning weight in Merino lines divergently selected for ewe multiple rearing ability. S. Afr. J. Anim. Sci. 33, 248-256.

Cloete, S.W.P., Schoeman, S.J., Coetzee, J. \& Morris, J.D., 2001. Genetic variances for liveweight and fleece traits in Merino, Dohne Merino and South African Mutton Merino sheep. Aust. J. Exp. Agric. $41,145-153$.

Duguma, G., Schoeman, S.J., Cloete, S.W.P. \& Jordaan, G.F., 2002. Genetic parameter estimates of early growth traits in the Tygerhoek Merino flock. S. Afr. J. Anim. Sci. 32, 66-75.

Gerstmayr, S., 1991. Impact of the data structure on the reliability of the estimated genetic parameters in an animal model with maternal effects. J. Anim. Breed. Genet. 109, 321-336. 
Gilmour, A. R., Gogel, B. J., Cullis, B. R., Welham, S. J. \& Thompson, R., 2014. ASReml User Guide Release 4.1 Structural Speci_cation, VSN International Ltd, Hemel Hempstead, HP1 1ES, UK. www.vsni.co.uk.

Hansen, C. \& Shrestha, J.N.B., 2002. Consistency of genetic parameters of productivity for ewes lambing in February, June and October under an 8-month breeding management. Small Rumin. Res. 44, 1-8.

Hatcher, S., Atkins, K.D. \& Thornberry, K.J., 2005. Age changes in wool traits of Merino sheep in Western NSW. Proc. Assoc. Advmt. Anim. Breed. Genet. 16, 314-318.

Herselman, M.J. \& Olivier, W.J., 2010. Description of a model for the calculation of breeding values for profitability. Grootfontein Agric. 10, 67-75.

Ingham, V.M., Ponzoni, R.W., Gilmour, A.R. \& Pitchford, W., 2003. Genetic parameters for weight, fat and eye muscle depth in South Australian Merino sheep. Proc. Assoc. Advmt. Anim. Breed. Genet. 15, 322-325.

Interbull, 2000. National Genetic Evaluation Programmes for Dairy Production Traits Practised in Interbull Member Countries, 1999-2000. Department of Animal Breeding and Genetics, Uppsala, Bulletin 24.

Jamrozik, J., Schaeffer, L.R. \& Dekkers, J.C., 1997. Genetic evaluation of dairy cattle using test day yields and random regression model. J. Dairy Sci. 80, 1217-1226.

Jawasreh, K., Ismail, Z.B., Iya, F., Castaneda-Bustos, V.J. \& Valencia-Posadas, M., 2018. Genetic parameter estimation for pre-weaning growth traits in Jordan Awassi sheep. Veterinary World 11, 254-258.

Kumar, S.I, Kumar V.C., Gangaraju, G., Nath, S \& Thiruvenkadan, A.K., 2017. Estimates of direct and maternal (co)variance components as well as genetic parameters of growth traits in Nellore sheep. Trop. Anim. Health Prod. 49, 1431-1438.

Lewer, R.P., Woolaston, R.R. \& Howe, R.R., 1994. Studies on Western Australian Merino sheep 2. Genetic and phenotypic parameter estimates for objectively measured traits on ram and ewe hoggets using different model types. Aust. J. Agric. Res. 45, 829-840.

Maniatis, N. \& Pollott, G.E., 2003. The impact of data structure on genetic (co)variance components of early growth in sheep, estimated using an animal model with maternal effects. J. Anim. Sci. 81, 101-108. 
Meyer, K., 1989. Restricted maximum likelihood to estimate variance components for animal models with several random effects using a derivative-free algorithm. Genet. Sel. Evol . 21, 317- 340.

Meyer, K., 2004. Scope for a random regression model in genetic evaluation of beef cattle for growth. Livest. Prod. Sci. 86, 69-83.

Meyer, K. \& Hill, W.G., 1997. Estimates of genetic and phenotypic covariance functions for longitudinal or 'repeated' records by restricted maximum likelihood. Livest. Prod. Sci. 47, 185-200.

Miraei-Ashtiani, S.R., Seyedalian, S.A.R. \& Shahrbabak, M.M., 2007. Variance components and heritabilities for body weight traits in Sangsari sheep using univariate and multivariate animal models. Small Rumin. Res. 73, 108-114.

Mohammadi, H., Shahrebabak, M.M. Shahrebabak, H.M., Bahrami, A. \& Dorostkar, M., 2013. Model comparisons and genetic parameter estimates of growth and the Kleiber ratio in Shal sheep. Archiv. Tierzucht 56 (2013) 26, 264-275

Morrell, C.H., 1998. Likelihood ratio testing of variance components in the linear mixed effects model using restricted maximum likelihood. Biomet. 54, 1560-1568.

Mortimer, S.I. \& Atkins, K.D., 1995. Maternal effects influence growth traits in Merino sheep. Proc. Aust. Assoc. Anim. Breed. Genet. 11, 421-424.

Murphy, T.W., Berger, Y.M., Holman, P.W., Baldin, M., Burgett, R.L. \& Thomas, D.L., 2017. Estimates of genetic parameters, genetic trends, and inbreeding in a crossbred dairy sheep research flock in the United States. J. Anim. Sci. 95, 4300-4309.

Ngere, L., Burke, J.M., Notter, D.R. \& Morgan, J.L.M., 2017. Variance components for direct and maternal effects on body weights of Katahdin lambs. J. Anim. Sci. 95, 3369-3405.

Olivier, J.J., 1989. Genetic and environmental trends in the Grootfontein Merino stud. Ph.D. thesis, University of the Orange Free State, Bloemfontein, South Africa.

Olivier, J.J. \& Cloete, S.W.P., 2011. Genetic (co)variances for yearling traits and reproduction in the South African Dohne Merino breed. Proc. Assoc. Advmt. Anim. Breed. Gen. 19, 167-170.

Olivier, J.J., Erasmus, G.J., Van Wyk, J.B. \& Konstantinov, K.V., 1994. Direct and maternal variance component estimates for clean fleece weight, body weight and mean frbre diameter in the Grootfontein Merino stud. S. Afr. J. Anim. Sci. 24(4), 122-124.

Olivier, J.J., Erasmus, G.J., Van Wyk, J.B. \& Konstantinov, K.V., 1995. Response to selection on BLUP of breeding values in the Grootfontein Merino stud. S. Afr. J. Anim. Sci. 25, 13-15. 
Olivier, W.J., 1998. Evaluation of ewe productivity measures. M.Sc. Agric. Thesis, University of the Orange Free State, Bloemfontein, South Africa.

Olivier, W.J., 2014. The evaluation of a South African fine wool genetic resource flock. PhD thesis, Stellenbosch University

Olivier, W. J., Cloete, S. W. P. \& Snyman, M. A., 2014. Genetic Relationships among Reproduction and Objective and Subjective Wool and Conformation Traits Measured in a Fine Wool Merino Stud. Proc. 10 $10^{\text {th }}$ World Congr. Genet. Appl. Livest. Prod. Vancouver, Canada. August 17 - 22, 2014

Olivier, W.J., Snyman, M.A., Olivier, J.J., Van Wyk, J.B. \& Erasmus, G.J., 2001. Direct and correlated responses to selection for total weight of lamb weaned in Merino sheep. S. Afr. J. Anim. Sci. 31, $115-121$.

Safari, E., Fogarty, N.M., Gilmour, A.R., Atkins, K.D., Mortimer, S.I., Swan, A.A., Brien, F.D., Greeff, J.C. \& Van der Werf, J.H.J., 2007a. Across population genetic parameters for wool, growth, and reproduction traits in Australian Merino sheep. 2. Estimates of heritability and variance components. Aust. J. Agric. Res. 58, 177-184.

Safari, E., Fogarty, N.M., Gilmour, A.R., Atkins, K.D., Mortimer, S.I., Swan, A.A., Brien, F.D., Greeff, J.C. \& Van der Werf, J.H.J., 2007b. Genetic correlations among and between wool, growth and reproduction traits in Merino sheep. J. Anim. Breed. Genet. 124, 65-72.

SAS Institute Inc., 2016. SAS OnlineDoc ${ }^{\circledR} 9.4$ Procedures Guide, Sixth Edition. Cary, NC: SAS Institute Inc.

Schwarz, G. 1978. Estimating the dimension of a model. Ann. Stat. 6, 461-464.

Singh, H., Pannu, U., Narula, H.K., Chopra, A., Naharwara, V. \& Bhakar, S.K., 2016. Estimates of (co)variance components and genetic parameters of growth traits in Marwari sheep. J. Appl. Anim. Res. 44, 27-35.

Snyman, M.A. \& Cloete, S.W.P., 2008. Lactation curves of wool sheep ewes under different grazing conditions. Grootfontein Agric. 8(1), 22-31.

Snyman, M.A., Erasmus, G.J., Van Wyk, J.B. \& Olivier, J.J., 1995. Direct and maternal (co)variance components and heritability estimates for body weight at different ages and fleece traits in Afrino sheep. Livest. Prod. Sci. 44(3), 229-236. 
Snyman, M.A., Olivier, J.J. \& Olivier, W.J., 1996. Variance components and genetic parameters for body weight and fleece traits of Merino sheep in an arid environment. S. Afr. J. Anim. Sci. 26, 11 14.

Thiruvenkadan, A.K., Chinnamani, K., Muralidharan, J. \& Karunanithi, K., 2008. Effect of non genetic factors on birth weight of Mecheri sheep of India. Livest. Res. Rural Dev. 20 (6).

Vaez Torshizi, R., Nicholas, F.W. \& Raadsma, H.W., 1996. REML estimates of variance and covariance components for production traits in Australian Merino sheep using an animal model 1. Body weight from birth to 22 months. Aust. J. Agric. Res. 47, 1235-1249.

Van Graan, A.C., Olivier, W.J. \& Herselman., M.J., 2014. Relative Economic Value for Merino Sheep in South Africa. Proc. $10^{\text {th }}$ World Congr. Genet. Appl. Livest. Prod.

Wolc, A., Barczak, E., Wójtowski, J., Slósarz, P. \& Szwaczkowski, T., 2011. Genetic parameters of body weight in sheep estimated via random regression and multi-trait animal models. Small Rumin. Res. 100, 15-18.

Wuliji, T.D.K., Dodds, K.G., Land, J.T.J., Andrews, R.N. \& Turner, P.R., 2001. Selection for ultrafine Merino sheep in New Zealand: heritability, phenotypic and genetic correlations of live weight, fleece weight and wool characteristics in yearlings. Anim. Sci. 72, 241-250.

Yavarifard, R., Hossein-Zadeh, N.G. \& Shadparvar, A.A., 2015. Estimation of genetic parameters for reproductive traits in Mehraban sheep. Czech. J. Anim. Sci. 60, 281-288. 